\title{
Citrumelos e citrandarins na região citrícola do Paraná
}

\author{
Ciro Daniel Marques Marcolini ${ }^{1}$, Eduardo Fermino Carlos $^{2}$, Silvia Blumer ${ }^{3}$, \\ Jorgino Pompeu Junior ${ }^{4} \&$ Mayra Costa Cruz de Carvalho ${ }^{5}$
}

\begin{abstract}
RESUMO
Existem vários motivos para a diversificação no uso de porta-enxertos no estado do Paraná, como a busca por indução de melhor qualidade de frutos, a resistência a estresses bióticos e abióticos, e outros. A baixa diversificação dos porta-enxertos na citricultura paranaense torna-a vulnerável à ocorrência de doenças. O principal porta-enxerto utilizado no Paraná é o limoeiro Cravo, que é suscetível ao declínio dos citros, à morte súbita e à gomose. A adoção de novos porta-enxertos, como os híbridos de trifoliata com pomelos ou tangerinas, os quais apresentam boa resistência a doenças e indução de boa qualidade de fruto podem tornar a citricultura mais sustentável a médio e longo prazos. Outras características importantes demandadas pelo setor citrícola se referem à plantas de porte baixo, com alta eficiência produtiva, produtoras de frutos com elevado teor de sólidos solúveis totais, casca fina, boa conservação pós-colheita e produção em épocas distintas. No estado americano da Flórida, em São Paulo, e em outras partes do mundo, citrumelos e citrandarins já foram testados e de modo geral apresentaram características de interesse do setor produtivo. Portanto, o conhecimento sobre genótipos de porta-enxertos, baseados em experiências prévias é de grande importância para o planejamento da diversificação e manutenção da sustentabilidade da citricultura paranaense.
\end{abstract}

Termos de indexação: Citrus, porta-enxerto, desenvolvimento vegetativo, qualidade do fruto.

\section{Citrumelos and citrandarins in the citrus region of Paraná}

\section{SUMMARY}

There are several reasons for diversification in the use of rootstocks in the state of Paraná, as the search for induction better fruit quality, resistance to biotic and abiotic stresses, and others. The low diversification of rootstocks in Paraná citrus make it vulnerable to the occurrence of diseases. The main rootstock used in Paraná is the Rangpur lime, which is susceptible to the decline of citrus, sudden death and gummosis. The adoption of new rootstocks, such as hybrid trifoliate with grapefruits or tangerines, which have good resistance to disease and good quality fruit induction can make more sustainable citrus production in the medium and long term. Other important features demanded by the citrus sector refer to short plants with high production efficiency, producing fruit

\footnotetext{
${ }^{1}$ Instituto Paranaense de Assistência Técnica e Extensão Rural - EMATER, Cornélio Procópio, PR, Brasil

${ }^{2}$ Departamento de Agronomia, Universidade Estadual Norte do Paraná - UENP, Bandeirantes, PR, Brasil

${ }^{3}$ Departamento de Melhoramento Vegetal, Instituto Agrônomico do Paraná - IAPAR, Londrina, PR, Brasil

${ }^{4}$ Centro de Citricultura Sylvio Moreira, Instituto Agronômico - IAC, Cordeirópolis, SP, Brasil

${ }^{5}$ Departamento de Fitopatologia e Nematologia Agrícola, Escola Superior de Agricultura Luiz de Queiroz - ESALQ, Universidade de São Paulo - USP, Piracicaba, SP, Brasil

Autor correspondente: Ciro Daniel Marques Marcolini, Emater Pr, Rua da Bandeira, 500 - Cabral, CEP 80035-270, Curitiba, PR, Brasil. E-mail: ciromarcolini@ emater.pr.gov.br
} 
with high content of soluble solids, thin skin, good post-harvest conservation and production at different times. In the American state of Florida, in São Paulo, and in other parts of the world, and citrumelos citrandarins have been tested and generally showed characteristics of interest to the productive sector. Therefore, Knowledge of rootstock genotypes, based on previous experience is of great importance for the planning of diversification and maintaining the sustainability of Paraná citrus industry.

Index terms: Citrus, rootstocks, citrandarins, vegetative growth, fruit quality.

\section{INTRODUÇÃO}

De acordo com a CitrusBR (Associação Nacional dos Exportadores de Sucos Cítricos), de cada cinco copos de suco de laranja consumidos no mundo, três são produzidos no Brasil, e as safras nacionais da fruta tem sustentado esse nível de hegemonia mundial. Também de acordo com a CitrusBR, a safra total 2013/2014 fechou em 289,9 milhões de caixas de 40,8 Kg, sendo que deste total, aproximadamente 50 milhões de caixas tiveram como destino os mercados in natura doméstico e de exportação, enquanto outras 240 milhões de caixas de laranja destinaram-se ao processamento pelas indústrias (CITRUSBR, 2014).

Para a safra 2015/2016, estima-se um total de laranja de 278,9 milhões de caixas de laranja de $40,8 \mathrm{~kg}$, aproximadamente 60 milhões de caixas a serem destinadas aos mercados doméstico e de exportação de fruta in natura, e 218,9 milhões de caixas de laranja devem ser destinadas ao processamento pelas indústrias (CITRUSBR, 2014). São Paulo é o maior produtor nacional, com uma produção de 11.873.426 toneladas (IBGE, 2013). Todos esses números fazem do Brasil o maior produtor mundial de laranja, e o segundo depois da China quando se considera todo o grupo citros (FAO, 2016).

O estado do Paraná é o quinto estado produtor do Brasil, possuindo em torno de 28.100 hectares de pomares, e uma produção de 927.300 toneladas (IBGE, 2013). No Brasil e também no estado do Paraná, uma preocupação que atinge todos os setores envolvidos com a citricultura, está na baixa diversificação de materiais genéticos levados ao campo, com poucas cultivares de copas sobre poucos porta-enxertos. O cultivo comercial de laranjeiras no estado do Paraná está concentrado principalmente nas regiões norte e noroeste, e têm como principais variedades de copa a Pêra, a Folha murcha e a Valência. O porta-enxerto mais utilizado para a laranjeira Valência e outras variedades cítricas, é o limoeiro Cravo, por ser tolerante ao déficit hídrico e induzir características agronômicas razoáveis às variedades copa, tanto em produtividade como em qualidade do fruto. Entretanto, o Cravo apresenta susceptibilidade à gomose, ao declínio dos citros (Carlos et al., 1997) e à morte súbita dos citros (Gimenes-Fernandes \& Bassanezi, 2001).

Em relação à qualidade dos frutos, a diversificação de cultivares copas e porta-enxertos é necessária para atender à demanda que exige frutos com maior teor de caldo $\mathrm{e}$ de sólidos solúveis, proporcionando um produto com melhor rendimento industrial, e também mais apreciado para o mercado de frutas frescas. Quando se trata de tentar diversificar cultivares de porta-enxertos, há o grande desafio de se encontrar algum genótipo melhor e mais produtivo que o limoeiro Cravo, pois os porta-enxertos são capazes de influenciar várias características nas árvores, em função da aptidão geral do respectivo sistema radicular de cada porta-enxerto às condições gerais de clima e solo da região da cultura (Pompeu Junior et al., 1981), determinando inclusive o tamanho e o vigor geral da copa (Pompeu Junior, 2001).

Analisando o ponto de vista da produção, há uma tendência de se adensar o plantio, utilizando-se genótipos que induzam um porte baixo no pomar comercial. Portanto, novos porta-enxertos que induzam ganhos em produtividade, precocidade e redução de custos por caixa de laranja produzida, terão ainda como outras vantagens a otimização do uso da mão de obra e das práticas culturais no campo (Pompeu Junior \& Blumer, 2011). Nesse sentido, o objetivo desta revisão bibliográfica foi a de caracterizar os citrumelos e os citrandarins, criados nos EUA e já testados em São Paulo (Pompeu Junior, 2009) como opções de porta-enxertos para a região citrícola do Paraná.

\section{DESENVOLVIMENTO E REVISÃO DE LITERATURA}

\section{Importância dos porta-enxertos na citricultura atual}

Os porta-enxertos tem uma grande importância na formação de uma planta cítrica, principalmente na laranja. Além de serem responsáveis pelo suporte das 
plantas, absorção de água e nutrientes, os porta-enxertos influenciam diversas características nas plantas, como tolerância ao stress hídrico, à acidez do solo e a alta saturação por alumínio (Neves., et al 2010).

A citricultura comercial exige frutos de boa qualidade, com alto teor de sólidos solúveis totais, acidez, bom rendimento industrial, casca lisa, frutos de tamanho médio, conservação pós-colheita, coloração da casca e dos frutos. É necessário também ter materiais produtivos com boa resistência a pragas e doenças, de porte baixo para permitir adensamento e produção em épocas distintas.

A introdução de novos porta-enxertos na citricultura do Paraná, como os citrandarins, que possuem tolerância ao declínio, ao viróide da exocorte e à tristeza (Pompeu Junior \& Blumer, 2009), e os citrumelos que apresentam características semelhantes aos citrandarins, podem ser fundamentais para tornar a citricultura paranaense mais sustentável e competitiva.

\section{Caracterização edafoclimática da região citrícola do estado do Paraná}

As condições edafoclimáticas influenciam significativamente o desenvolvimento e a produção das diferentes espécies do gênero Citrus. No estado do Paraná, a partir do zoneamento edafoclimático, se destacaram quatro regiões aptas ao cultivo desta cultura. A região noroeste $\left(22^{\circ} 30^{\prime} \mathrm{S}\right.$ a $24^{\circ} 0^{\prime} \mathrm{S}$ e $54^{\circ} 0^{\prime} \mathrm{W}$ a $\left.51^{\circ} 30^{\prime} \mathrm{W}\right)$, que possui predominância de solos de textura arenosa, a região do médio Paranapanema (22 $30^{\circ} \mathrm{S}$ a $23^{\circ} 30^{\prime} \mathrm{S}$ e $50^{\circ} 30^{\prime} \mathrm{W}$ a $\left.51^{\circ} 30^{\prime} \mathrm{W}\right)$ com solos de textura argilosa e arenosa, a região nordeste $\left(23^{\circ} 0^{\prime} \mathrm{S}\right.$ a $24^{\circ} 0^{\prime} \mathrm{S}$ e $50^{\circ} 30^{\prime} \mathrm{W}$ a $49^{\circ} 30^{\prime} \mathrm{W}$ ) com predominância de solos de textura arenosa e a região centro-norte $\left(23^{\circ} 0^{\prime} \mathrm{S}\right.$ a $24^{\circ} 0^{\prime} \mathrm{S}$ e $50^{\circ} 30^{\prime} \mathrm{W}$ a $51^{\circ} 30^{`} \mathrm{~W}$ ) com predomínio de solos de textura argilosa (Fritzsons et al., 2011).

De uma forma geral, os solos de textura argilosa dificultam o crescimento do sistema radicular e em consequência reduzem a velocidade de crescimento e o tamanho das plantas, os frutos são menores, com menos caldo, mais ricos em açucares e ácidos e com maturação mais tardia. Nos solos de textura arenosa, ocorre o inverso (Donadio, 1988). As altitudes variam em média entre 440 metros a 600 metros, com ocorrência de altitudes extremas de 350 metros e 800 metros, e um nível de precipitação anual entre 1090 a 1593 mm (Fritzsons et al., 2011). Por serem regiões com grande acumulação de unidades de calor (graus dias), e amplitude térmica, temos uma alta probabilidade para termos frutos com coloração mais amarelada.

Diante da variabilidade edafoclimática existente no estado, é provável que diferentes genótipos de porta-enxertos possam expressar o seu máximo potencial tanto em termos de produtividade como em qualidade em regiões distintas. Em trabalhos conduzidos na região noroeste do Estado para avaliação de porta-enxertos com copas de laranjeira Folha Murcha (Stenzel et al., 2005) e de laranjeira Valência (Auler et al., 2008; Auler, 2010) tem-se observado resultados diferentes dos obtidos em outras regiões de cultivo (Pompeu Junior, 2001; Stuchi et al., 2000).

Essas diferenças são atribuídas, entre outros aspectos, à menor deficiência hídrica observada no Paraná em relação, por exemplo, à região mais tradicional de cultivo do Estado de São Paulo (Sentelhas et al., 1999), onde a maioria dos trabalhos envolvendo a avaliação de porta-enxertos foi desenvolvida. Por essa razão, nessas regiões do Paraná o desempenho de porta-enxertos como as tangerineiras Sunki e Cleópatra, e certos híbridos de trifoliata têm apresentado desempenho em produção semelhante ao Cravo em condições de sequeiro. Contudo, a ocorrência de estresses hídricos nessas regiões, embora com menor intensidade em relação ao Norte de São Paulo e Triângulo Mineiro, especialmente em períodos críticos para a definição da safra, como florescimento e pegamento de frutos, podem demandar ensaios de competição de cultivares com novos porta-enxertos para essas regiões, inclusive contrastando condições de sequeiro e sob irrigação. Assim, também existe interesse em avaliações de novos porta-enxertos sob condições normais de cultivo e sob irrigação.

\section{Compatibilidade copa $\mathbf{x}$ porta-enxerto}

O procedimento que envolve o processo da enxertia, decorre da união de dois genótipos geneticamente distintos, que passam a compartilhar uma série de fatores essenciais à sobrevivência de ambos. Este relacionamento é considerado como simbiótico, mutuamente benéfico, embora os interesses e necessidades da copa e do porta-enxerto nem sempre sejam comuns. O ganho esperado no desempenho da copa está em função da eficiência do porta-enxerto utilizado e da afinidade dos tecidos de ambos. Esta compatibilidade é fundamental para o sucesso ao longo do tempo de um pomar comercial (Carlos et al., 1997). No entanto, alguns cultivares cítricos, quando enxertados sobre certos porta-enxertos, demonstram pouca afinidade em relação a 
estes. Combinações de copas e porta-enxertos incompatíveis apresentam na região de enxertia, externamente, uma linha de depressão na casca acompanhada por uma brotação anormal do porta-enxerto (Carlos et al., 1997).

Segundo Oliveira Junior (1999), duas plantas são incompatíveis quando, por motivos intrínsecos a elas, não são capazes de formar uma união completa e equilibrada, impossibilitando o desenvolvimento normal da planta. Esta incompatibilidade surge em vista das diferenças nas características dos crescimentos da copa e do porta-enxerto, diferenças fisiológicas e bioquímicas entre os dois e à produção de alguma substância tóxica de uma parte para a outra, e Rodrigues et al. (2001), estudando a compatibilidade da enxertia em Prunus sp, concluíram que a atividade de peroxidase e a elevada concentração de fenóis estão relacionadas com a união incompatível entre enxerto e porta-enxerto. Em experimento realizado em Cordeirópolis, Barbasso et al. (2005) observou a ocorrência de linha de goma na região de enxertia para o tangor 'Murcott' sobre o citrumelo 'Swingle' após 10 anos de plantio, mostrando incompatibilidade em plantas formadas com essa combinação.

Grant et al. (1957) descreveu a ocorrência de incompatibilidade em plantas de laranja Pêra enxertadas em trifoliata e limão Rugoso da Flórida. Os sintomas da anormalidade se caracterizam pela formação de uma linha de goma no tronco, na união copa porta-enxerto, com saliências na face interna da casca, com a ocorrência de depressões na madeira. Normalmente, as árvores afetadas entram em declínio e morrem precocemente ou permanecem nanicas no pomar, e segundo Pompeu Junior \& Blumer (2005) dois outros citrumelos também evidenciaram incompatibilidade com a laranja Pêra (F80-3 e F80-5), ambos com os mesmos parentais que o citrumelo Swingle.

\section{Influência dos porta-enxertos sobre as características de crescimento das plantas}

A nova citricultura busca genótipos de porta-enxertos que reduzam a altura das plantas. Plantas de citros menores e com alta eficiência produtiva permitem maior densidade de plantio e maior produtividade. A altura menor das plantas permite otimizar a inspeção de pragas e doenças e melhora significativamente a eficiência das pulverizações e várias características horticulturais (Carlos et al., 1997). Os pomares adensados e de menor porte tem também a perspectiva de retorno econômico inicial mais cedo, e maior facilidade de colheita, devido ao aumento no rendimento do colhedor no campo (Castle., et al 2010).

De modo geral, existe a necessidade de se encontrar novas opções de porta-enxertos menos vigorosos, mas mais eficientes que os em uso. O próprio trifoliata, para o qual, na região noroeste do Paraná foram obtidos resultados que indicam boa eficiência de produção em sequeiro com copa de Valência, a partir de uma densidade teórica projetada de 490 plantas ha $^{-1}$ (Auler, 2010), precisa ainda ser testado sob condições de maior densidade de plantas/área. Nessas condições, é provável que a maior demanda por água possa prejudicar o desempenho do trifoliata e de seus híbridos sob sequeiro.

Em São Paulo, Pompeu Junior (2009) demonstrou que de treze porta-enxertos avaliados, aos 16 anos de idade, seis induziram a formação de plantas com alturas iguais ou inferiores a 2,5 metros, o que indica que são porta-enxertos nanicantes. Neste mesmo experimento, Pompeu Junior (2009) relatou diferenças de 52\% de crescimento em laranjeira Valência entre o porta-enxerto com a maior altura e a menor. Em Cordeirópolis, as laranjeiras Valência enxertadas em citrumelos foram significativamente menores que as formadas sobre outros porta-enxertos. Todos obtiveram alturas inferiores à 2,5 $\mathrm{m}$ após seis anos de experimento, sendo por isso considerados potencialmente nanicantes (Pompeu Junior \& Blumer, 2011).

\section{Influência dos porta-enxertos sobre a qualidade do fruto}

Os porta-enxertos tem efeito significativo no desenvolvimento do fruto, e a habilidade em fornecer agua para a planta se destaca como a principal influência, seguida pelo fornecimento de nutrientes (Albrigo, 1992). Os genótipos sobre porta-enxertos pouco vigorosos, tem menor desenvolvimento vegetativo e apresentam uma tendência para produzir frutos menores, com a casca mais lisa e alto conteúdo de sólidos solúveis e ácidos no suco. Porta-enxertos vigorosos são melhores extratores de umidade do solo e mantém a planta sob menor pressão de água, o mesmo ocorrendo com a irrigação (Albrigo, 1992).

Os teores de açúcares solúveis presentes nos frutos destes materiais influenciam diretamente no rendimento industrial, pois a quantidade de açucares na fruta, determina o número de caixas de laranja necessário para produzir suco concentrado. Os porta-enxertos, juntamente com os fatores edafoclimáticos, além da adubação e tratos 
culturais influenciam o tamanho e o peso dos frutos, côr e espessura da casca, conteúdo do suco, sólidos solúveis totais (Brix), acidez e outros (Stuchi et al., 1996). Segundo (Stenzel et al., 2005), em sete porta-enxertos com copa Folha murcha no Noroeste do Paraná, foram registrados acréscimos de 16\% nos sólidos solúveis totais, o que proporcionou uma variação de até $28 \%$ na diferença do ratio entre os porta-enxertos.

\section{Distribuição dos citrumelos e citrandarins em outras partes do mundo}

Um dos métodos para a obtenção de plantas nanicas é a utilização de portaenxertos nanicantes, entre os quais os citrandarins e os citrumelos, que também proporcionam frutos de melhor qualidade. Os citrandarins são utilizados em diversos países: na África do Sul, Cleópatra x trifoliata (C. reshni hort. ex Tan. x P. trifoliata Raf.) cv. X639; Estados Unidos, 'Changsha' $\mathrm{x}$ 'English' large (C. reticulata Blanco x P. trifoliata Raf.) cv.US815, 'Sunki' x 'Benecke' [C. sunki (Hayata) hort. ex Tan. x P. trifoliata] cv. US812, e 'Cleópatra' x 'Flying Dragon' (US897) [C. reshni hort. ex Tan. x P. trifoliata var. monstrosa (T. Ito) Swingle cv. US897; e, na Espanha, 'Cleópatra' x trifoliata (Forner \& Alcaide5) e (F\&A13) (Pompeu Junior \& Blumer, 2009).

Dentre os citrumelos, se destaca principalmente o Swingle. O citrumelo Swingle foi introduzido em São Paulo na década de 1940, pelo Instituto Agronômico, e mostrou induzir boa produtividade às laranjeiras (Pompeu Junior, 2011). Foi muito plantado nos Estados Unidos (Hutchison, 1974) e hoje também no Brasil. Devido ao sucesso alcançado pelo citrumelo Swingle, foram criados os citrumelos das séries F80 e F81, também muito plantados nos Estados Unidos (Castle et al., 1988), e que tem se mostrado similares ao Swingle (Castle et al., 1988).

\section{Características gerais dos porta enxertos derivados de citrumelos e citrandarins}

Os citrandarins são plantas híbridas resultantes do cruzamento entre microtangerinas como a Sunki ou a Cleópatra, com o trifoliata. Genótipos criados pelo USDA, Flórida (EUA), foram importados e avaliados para produção e qualidade de frutos na região de Pirassununga, SP (Pompeu Junior et al., 2002). A intenção do melhorista foi reunir em um mesmo material as qualidades das tangerinas como tolerância ao declínio, ao viróide da exocorte e a solos calcários, às qualidades dos trifoliatas, como imunidade à tristeza, resistência à gomose e ao frio (Pompeu Junior, 2009).

Além disso, os citrandarins, de um modo geral, induzem às copas produção de frutos com melhores características comerciais, como alta produção de sólidos solúveis totais, alta produção de frutos por metro cúbico de copa e indução de plantas com porte baixo. Em experimento conduzido em Itirapina-SP, com treze diferentes materiais, o citrandarin Cleópatra x Christian, após seis anos de experimento, induziu a formação de plantas com média de altura de 1,9 metros, e os híbridos Clementina x trifoliata, Cleópatra x Swingle (715), Cleópatra x Swingle (1614), Cleópatra x Rubidoux (1600) e Cravo x Carrizo induziram a formação de plantas com alturas iguais ou inferiores a 2,5 metros, o que indica que são porta-enxertos nanicantes (Pompeu Junior, 2009).

No estado de São Paulo, resultados mostraram que os citrandarins mais promissores foram HRS 801 (Changsha x English Small) e HRS 812 (Sunki x Benecke). Estes demonstraram ser tolerantes à tristeza e ao declínio, apresentaram boa resistência à gomose e ao nematóide dos citros, e induziram à laranjeira 'Valência' produções de frutos $152 \%$ e $79 \%$ e de sólidos solúveis $176 \%$ e $105 \%$, respectivamente, maiores que as obtidas com o trifoliata Davis A (Blumer \& Pompeu Junior, 2005).

Em uma avaliação de 11 citrandarins em comparação com os citrangeiros Troyer e Carrizo, verificaram que pelo menos cinco deles foram superiores aos citranges, considerando as cinco primeiras safras avaliadas com copa de Valência, incluindo o híbrido Cleópatra x English. O híbrido Cleópatra x Rubidoux (acesso 1600), não diferiu dos citrangeiros em produção. Houve diferença entre os híbridos quanto à resistência à gomose de $P$. parasitica, entre os quais se inclui o híbrido Cleópatra x Rubidoux. Nenhum híbrido apresentou sintomas de intolerância à tristeza e ao declínio dos citros até os oito anos após o plantio (Blumer \& Pompeu Junior, 2005). Em 1907, Walter T. Swingle promoveu um cruzamento entre o pomelo 'Duncan' e um trifoliata, inicialmente denominado CPB 4475 , posteriormente adquiriu o nome de seu criador (Hutchison, 1974).

O sucesso do citrumelo Swingle na Flórida estimulou o pesquisador Mortimer Cohen, da Universidade da Flórida, a repetir em 1955 o cruzamento que originou o citrumelo Swingle, dando como resultado novos citrumelos, designados F80 e F81 (Castle et al., 1988). O citrumelo Swingle tem apresentado tolerância ao vírus da tristeza, à gomose e se mostra moderadamente tolerante 
a solos salinos (Hutchison, 1974), e os citrumelos das séries F80 e F81 tem se mostrado similares ao Swingle (Castle et al., 1988).

Outras características importantes, como tolerância ao declínio, exocortis e xiloporose, boa tolerância ao frio e ao nematoide também foram observadas (Castle et al., 1988). A redução do porte da planta também é uma característica associada a estes materiais (Hutchison, 1974), o que também foi constatado em Cordeirópolis-SP, onde todos os citrumelos mostraram-se nanicantes, por terem proporcionado laranjeiras com alturas inferiores a 2,5 metros (Pompeu Junior \& Blumer, 2011). A cor e a qualidade do suco produzida pelo citrumelo Swingle são iguais ou melhores do que as frutas de árvores sobre laranja Azeda, citrange Carrizo e Cleópatra (Castle et al., 1988), e em São Paulo, as cultivares enxertadas sobre o Swingle produzem frutos de qualidade superior àquelas obtidas sobre os limões Cravo e Volkameriano (Pompeu Junior \& Blumer, 2005).

\section{CONCLUSÕES}

Dentre as opções de híbridos apresentados neste trabalho que potencialmente poderão ser usados no estado do Paraná, supõem-se que alguns genótipos possuam características superiores em relação aos porta-enxertos atualmente em uso. Diante do exposto, recomenda-se avaliar o desempenho de cada genótipo de porta-enxerto sob condições de sequeiro e irrigado nas diversas localidades edafoclimáticas na região citrícola do estado do Paraná.

\section{REFERÊNCIAS}

Albrigo G (1992) Influências ambientais no desenvolvimento dos frutos cítricos. Anais do II Seminário Internacional de Citros - Fisiologia, Campinas, SP, p. 100-106.

Auler PAM (2010) Preparo do solo, calagem e portaenxertos para o cultivo de laranjeira 'Valência'. Tese de Doutorado, Universidade Estadual de Londrina, Londrina.

Auler PAM, Fiori-Tutida ACG \& Tazima ZH (2008) Comportamento da laranjeira 'Valência' sobre seis portaenxertos no noroeste do Paraná. Revista Brasileira de Fruticultura 30(1): 229-234.

Barbasso DV, Pio RM \& Carvalho SA (2005) Compatibilidade de variedades e híbridos de tangerinas enxertadas em citrumelo 'SWINGLE'. Revista Laranja, 59-67.
Blumer S \& Pompeu Junior J (2005) Avaliação de citrandarins e outros híbridos de trifoliata como portaenxertos para citros em São Paulo. Revista Brasileira de Fruticultura 27(2): 264-267.

Carlos EF, Stuchi ES \& Donadio LC (1997) Porta-enxertos para a citricultura paulista. Jaboticabal: FUNEP, 47 p. (Boletim Citrícola, 1).

Castle WS, Wutscher HK, Youtsey CO \& Pelosi RR (1988) Citrumelos as rootstocks for Florida citrus. Proceedings of the Annual Meeting of the Florida State Horticultural Society 101: 28-33.

CITRUSBR - Associação Nacional dos Exportadores de Sucos Cítricos (2014) Revisão dos dados estimados de fechamento da safra 2013/14. Disponível em: <www. citrusbr.com>. Acesso em: 19 ago. 2015.

FAO - Organização das Nações Unidas para a Alimentação e a Agricultura (2016) Press Release FAO. Disponível em: $<$ http://www.fao.org/brasil/pt/>. Acesso em: 17 abr. 2016.

Fritzsons E, Bolognola I, Mantovani LE, Wrege M, Carvalho Junior W \& Chagas CS (2011) Cartas de unidades edafoclimáticas para o estado do Paraná para plantios florestais. Colombo: Embrapa Florestas. (Embrapa Florestas. Documentos, 223).

Gimenes-Fernandes N \& Bassanezi RB (2001) Doença de causa desconhecida afeta pomares cítricos no norte de São Paulo e sul do Triângulo Mineiro. Summa Phytopathologica 27: 93.

Grant TJ, Moreira S \& Costa AS (1957) Observations on abnormal citrus rootstock reactions in Brazil. Plant Disease Reporter 41: 743-748.

Hutchison DJ (1974) Swingle citrumelo - a promising rootstock hybrid. Florida State Horticultural Society, 89-91.

IBGE - Instituto Brasileiro de Geografia e Estatística (2013) Levantamento Sistemático da Produção Agrícola Junho 2015 - Informações sobre culturas permanentes. Disponível em <www.ibge.gov.br>. Acesso em: 20 ago. 2015.

Neves MF, Trombim VG, Milan P, Lopes FF, Cressoni F \& Kalaki R (2010) O retrato da citricultura brasileira. São Paulo: CITRUSBR.

Oliveira Junior ME (1999) Produtividade e características físico-químicas dos frutos da tangerineira 'Ponkan' (Citrus reticulata Blanco) sobre 14 porta-enxertos na Vargem Bonita, D.F. Dissertação de Mestrado, Faculdade de Agronomia e Medicina Veterinária, Universidade de Brasília, Brasília. 
Pompeu Junior J \& Blumer S (2005) Performance de citrumelos F80 no Estado de São Paulo. Revista Laranja 26(1): 77-85.

Pompeu Junior J \& Blumer S (2011) Citrumelos como portaenxertos para laranja 'Valência'. Pesquisa Agropecuária Brasileira 46(1): 105-107.

Pompeu Junior J (2001) Porta-enxertos para citros potencialmente ananicantes. Revista Laranja 22(1): 147-155.

Pompeu Junior J (2005) Porta-enxertos. In: Mattos Junior D, DeNegri JD, Pio RM, Pompeu Junior J (Orgs). Citros. Cordeiropolis: Centro APTA Citros Sylvio Moreira, v. 1, p. 63-104.

Pompeu Junior J (2009) Híbridos de trifoliata como porta-enxertos para a laranjeira 'Valência'. Pesquisa Agropecuária Brasileira 701-705.

Pompeu Junior J, Figueiredo OJ, Sobrinho JA, Igue T \& Salibe AA (1981) Comportamento da laranjeira Valência Citrus sinensis (L.) Osbeck, em 18 porta-enxertos. Anais do VI Congresso Brasileiro de Fruticultura, Recife, v. 2, p. $530-541$.

Pompeu Junior J, Laranjeira FF \& Blumer S (2002) Laranjeiras 'Valência' enxertadas em híbridos de Trifoliata. Scientia Agrícola 59(1): 93-97.
Rodrigues AC, Machado LB, Diniz AC, Fachinello JC \& Fortes GRL (2001) Avaliação da incompatibilidade da enxertia em Prunus sp. Revista Brasileira de Fruticultura 23(2): 359-364.

Sentelhas PC, Pereira AR, Marin FR, Angelocci LR, Alfonsi RR, Caramori PH \& Swart S (1999) BHBRASIL - balanços hídricos climatológicos de 500 localidades brasileiras. Piracicaba: ESALQ/USP, 7 p.

Stenzel NMC, Neves CSVJ, Scholz MBS \& Gomes JC (2005) Comportamento da laranjeira 'Folha Murcha' em sete porta-enxertos no Noroeste do Paraná. Revista Brasileira de Fruticultura 27(3): 408-411.

Stuchi ES \& Sempionato OR, Silva JAA (1996) Influência dos porta-enxertos na qualidade dos frutos cítricos. Revista Laranja 17(1): 159-178.

Stuchi ES, Donadio LC \& Sempionato OR (2000) Avaliação da laranjeira 'Folha Murcha' (Citrus sinensis (L) Osbeck) sobre dez porta-enxertos em Bebedouro-SP. Revista Brasileira de Fruticultura 22(3): 446-453.

Recebido: Julho 14, 2016 Aceito: Julho 03, 2017 